\title{
Contextos, trocas e utopias: Literaturas brasileira e angolana em diálogo
}

Maria Geralda de Miranda ${ }^{1}$

RESUMO: Os estudos das Literaturas africanas têm contribuído de forma decisiva para a formação de profissionais com uma visão mais ampla no que tange aos contributos culturais dos africanos à identidade brasileira. $\mathrm{O}$ volume de estudos e a ação de alguns pesquisadores também foram decisivos para que se elaborasse e aprovasse a lei 10.639. A atitude política contida na elaboração da lei e os efeitos dela advindos abrem caminho para reduzir as dívidas históricas do Brasil consigo próprio e especialmente para com os africanos e afrodescendentes. Estudar as literaturas africanas de língua Portuguesa, observando as relações dialogais com a literatura brasileira contribuirá para a compreensão acerca do nosso próprio imaginário nacional, já que, segundo Hussel Hamilton (2003), "a partir do fim do século XIX e ao longo das décadas, até o presente, a expressão literária brasileira e a percepção do Brasil por escritores e intelectuais da África portuguesa vêm tendo uma visível importância entre angolanos, cabo-verdianos, guineenses, moçambicanos e são-tomenses". Assim, buscar-se-á, através do presente estudo, estabelecer diálogos entre as escritas do angolano Pepetela e do brasileiro João Ubaldo Ribeiro.

PALAVRAS-CHAVE: Imaginário, Utopias, Brasil, Angola

A narrativa contemporânea, especialmente aquela que se tece na articulação entre memória, ficção e história e que é denominada por alguns críticos de metaficção historiográfica, tem sido já há algum tempo objeto de nossas pesquisas, principalmente por vermos tais narrativas como um espaço privilegiado onde se encenam os grandes questionamentos vivenciados pelo homem da atualidade.

Como é sabido, através das lições de Linda Hutcheon (1991), as narrativas metaficcionais historiográficas lançam no passado, trazido para o presente, o olhar da "desconfiança" sobre eventos e heróis consagrados da historiografia. O fim das certezas contamina o passado, destruindo-lhe a "aura" conferida pelo registro histórico. A "manipulação" do passado, pela pena dos autores contemporâneos, produz no leitor a reflexão sobre o fim das certezas e leva-o ao questionamento sobre as consagradas "verdades históricas". A epígrafe de Viva o povo brasileiro, de João Ubaldo Ribeiro, "O segredo da verdade é o seguinte: não existem fatos, só existem histórias”, por si só, já exemplifica o que estamos querendo dizer. Questiona-se com ela, ou a partir dela, a

${ }^{1}$ mariamiranda@globo.com

Caderno Seminal Digital Ano 16, nº 13, V. 13 (Jan.- Jun/2010) - ISSN 1806 -9142 
objetividade tão apregoada do fato histórico, pois, em tal romance, se estabelece um contraste entre a versão oficial da história e a experiência daqueles que vivem, sofrem e fazem a história, mas que não têm lugar em suas páginas.

A romance Viva o povo brasileiro, apesar de cobrir das origens da nação brasileira aos finais dos anos 70 do século XX, centra a sua ação principalmente no Século XIX, marcado pela afirmação de um sentimento nacional que alimentou as lutas internas e externas. (OLIVIERI-GODET, 2003). À exceção do segundo capítulo que localiza a ação no século XVII - são as cenas rememoradas pela personagem Dadinha e dos dois últimos que contemplam os dois períodos de ditadura do século $\mathrm{XX}$, todos os outros dezessete, num total de vinte, situam a ação no século XIX, abarcando

as lutas pela independência, o Império, a abolição da escravatura, a República, a guerra do Paraguai, a guerra dos Farrapos, a campanha contra Canudos, todos esses fatos são revistos a partir de um confronto entre o discurso da História e a versão popular, fundamentada na experiência de vida dos personagens.(OLIVIERI-GODET, 2003).

Em A geração da utopia, a efabulação se desenvolve em quatro momentos. "A casa" (1961), “A chana" (1972), "O polvo" (1982) e "O templo" (a partir de julho de 1991), mas o título do romance já de imediato nos fornece importantes pistas de leitura. A geração de que fala Pepetela possuía um discurso carregado de certezas, era condicionada pelo enfoque sociológico de orientação marxista e acreditava que as suas idéias e as suas ações seriam capazes de redimir os colonizados dos sofrimentos seculares impostos pelos colonizadores.

No capítulo "A casa" (referência à Casa dos Estudantes do Império - CEI), narra-se o amadurecimento das idéias da utopia. No capítulo intitulado "A chana", falase sobre a luta armada, a partir da atuação da personagem Vitor Ramos, cujo codinome é Mundial. Em “O polvo", representa-se o exílio de Sábio e suas críticas ferrenhas aos dirigentes da recente nação angolana. No capítulo denominado "O templo", encenam-se os conchavos e as falcatruas realizadas por dirigentes, candongueiros e falsos líderes religiosos. A fundação da igreja de dominus que se constitui como "metáfora extremada" do poder absoluto do partido e dos dirigentes - que tem seguidores fanáticos titerizados - encerra o último capítulo da obra. A ortodoxia no plano políticoideológico e a corrupção dos que assumiram o poder, bem como as incertezas do narrador quanto às certezas anteriormente defendidas, pontuam o fim do romance. 
Apesar da alegórica igreja de dominus e do fracasso da experiência administrativa dos dirigentes angolanos, não podemos, no entanto, afirmar que o romance proclama a morte da utopia, entendida como crença na possibilidade de uma sociedade mais justa. Tanto é que Sábio prefere o isolamento a ter que participar do governo, abre mão dos privilégios oferecidos pelo poder, questiona até mesmo a parca pensão militar que recebe. A sua conduta faz dele uma personagem desenhada ideologicamente para viver a utopia, porque preparada para renunciar àquilo que iguala a imensa maioria dos homens, que é o desejo de acumular riquezas. O que temos no romance é o fim de utópicas idéias, mas não a morte da utopia. A conversa entre Sara e Sábio, quando este foi visitá-la em Luanda, comprova isso. Diz Sábio: "Um dia terei que procurar outra baía mais para o sul, sempre mais para o sul. Será o sul a minha última utopia?" (PEPETELA, 1993, p. 308).

Em outro estudo sobre outras obras do autor angolano, Pepetela, consideramos o romance Yaka como metáfora da própria nação angolana. Relendo-o, no momento atual, juntamente com A geração da utopia, vemos que a história contada nas páginas desse último romance desconstrói aquela narrativa que ousamos chamar narrativanação.

Tal narrativa, construída euforicamente em Yaka, sob a égide das idéias revolucionárias, é questionada em A geração da utopia, que não faz uma crítica expressa ao marxismo, mas aos dirigentes do MPLA que não conseguiram promover a justiça social em Angola, após a implantação do estado-nação socialista. Pelas lentes da personagem Sábio, vê-se a corrupção no governo angolano e o enriquecimento ilícito dos dirigentes. Pelo expediente discursivo da paródia, verifica-se que os detentores das falas mais radicalizadas, na época em que eram estudantes, são os que mais rapidamente abandonaram os ideais da utopia. Os personagens Mundiais e Elias são exemplos desse tipo de comportamento.

O texto de Pepetela, por abordar a nação angolana ainda na trama urdida por intelectuais colonizados, influenciados pelo ideário marxista, em sua vivência na Casa dos Estudantes do Império, quer também ironizar a ditadura salazarista e a representação oficial da história, que via e tratava a Casa como espaço simbólico privilegiado de reprodução do ideário imperial e não como o locus em que se tramavam várias revoluções que levaram o império ao seu fim. 
$\mathrm{Na}$ verdade, a Casa dos Estudantes era exatamente o local em que se tramava contra a hegemonia colonial portuguesa, nas conversas durante as partidas de jogo com Amílcar e Agostinho, dois grandes heróis das lutas de independência, forjados no ideário da utopia, de que nos fala Pepetela. Os estudantes estavam pensando em hegemonia, sim, mas de outras nações - as que eles iriam edificar - e por isso conspiravam no lugar criado para evitá-las. É claro que essa cena ridiculariza o ditador português, que não conseguia enxergar "as nações que se urdiam” à sua porta.

$\mathrm{O}$ romance Viva o povo brasileiro questiona principalmente o discurso historiográfico unilateral e exclusivo da nação. É a opção do enunciador pelo ponto de vista plural, ao permitir que personagens sem voz na história oficial falem, que produz o entrecruzamento entre história, memória e ficção no romance. A palavra é franqueada pelo narrador a várias personagens que pertencem à camada popular. Tais personagens, a partir de suas vivências e experiências, vão construindo um liame identitário e ideológico-cultural que une passado, presente e futuro. Assim, “o que a ficção propõe é uma reposição dos fatos: confrontando as versões oficial e popular, a ação imprime autenticidade à última e desmoraliza a primeira"(OLIVIERE-GODET, ). É o caso exemplar da história do falso heroísmo de Perilo Ambrósio que é desautorizada pelo narrador e pela versão do negro Feliciano ou, ainda, a falsa morte heróica do alferes Brandão Galvão e os igualmente falsos discursos a ele imputados.

Fora mesmo através dele que todos souberam em pormenores como morrera Inocêncio no campo de Pirajá, com o sangue roubado pelo Barão para falsificar sua glória de guerra, e souberam como tinha sido cortada a língua de Feliciano, mesmo ele tendo chorado e jurado por todos os santos brancos que se o poupassem jamais diria uma palavra sobre o assunto. Mas não adiantou - contou Feliciano. (RIBEIRO, 1984, p. 157)

No fragmento acima, pela voz irônica do narrador, somos informados do modo pelo qual Perilo Ambrósio conseguiu passar-se como "bravo" combatente na Batalha do Pirajá. Além de matar Inocêncio para lambuzar-se com o seu sangue e fingir que fora ferido na batalha, ainda cortou a língua de Feliciano, receoso de que este falasse sobre o acontecido. Estamos de acordo com Magdelaine Ribeiro que afirma que, num primeiro eixo de leitura, o romance gira em torno do papel dos heróis na construção da identidade nacional. E que, de fato,

a nação aparece aí como um fato discursivo controvertido, uma vez que, para alguns, a sua existência é antes de tudo geográfica 
e antropológica e é lutando contra o estrangeiro que se forja o sentimento nacional, enquanto, para outros, a consciência nacional é indissociável do fato de pertencer a uma irmandade, a do povo brasileiro que não se reconhece plenamente nessas lutas. (RIBEIRO, 2003)

Nós acrescentaríamos à análise de Magdelaine que tanto na primeira construção, a da existência geográfica e antropológica, quanto na segunda abre-se um espaço para discursos e sentimentos nacionais variados. Ideologicamente, os interesses que sustentam a idéia de estado-nação, num primeiro momento, dizem respeito principalmente às elites colonialistas do país que já desfrutavam dos privilégios proporcionados pelo sistema vigente. Após a independência do Brasil, o poder praticamente não trocou de mão. Muito pelo contrário, com ela, conferiu-se mais poder (através de títulos de nobreza, por exemplo) a quem já o possuía, como é o caso do Barão de Pirapuama.

Para os escravos, concretamente, nada mudou. Mas a retórica da unidade nacional está presente nos discursos das elites em todos os momentos conturbados da história criada por João Ubaldo, ou por ele vertida. Não apenas tal retórica foi usada para libertar-se do colonizador (conferir o discurso imputado ao alferes Brandão Galvão), como também para evitar a invasão ao estado pátrio (os discursos de João Popó, por exemplo). Ela foi usada igualmente para combater campanhas separatistas (guerra dos Farrapos) ou ainda para aniquilar movimentos sociais reivindicatórios, seja de classe, ou não (guerra de Canudos, etc). Exalta-se a idéia de um povo espalhado pelo extenso território nacional, seja para implantar a República, seja - outro exemplo - para impor ditaduras militares ou ainda para fazer a abertura política, lenta ou gradualmente.

Se, por um lado, no romance, as elites sempre souberam usar o sentimento nacional para permanecer no poder e sempre se valeram do poder político, tendo em vista interesses econômicos, por outro, o povo, representado pela linhagem de Dadinha, tem, na irmandade do povo brasileiro, a esperança de que a nação seja plural e que haja espaço também nela para ele, o povo, pois, afinal de contas, é ele que a constrói. A conversa de Maria da Fé com Budião revela esta crença:

A irmandade fazia parte da vida deles, lhes dera sempre alento animação e esperanças, chegara mesmo parecer confirmar-se várias vezes (...) Por que estavam mesmo lutando? Por que lutara ele na província, conseguindo uma alforria que de nada lhe valera? (...) Ele mesmo acreditava na liberdade, tanto assim que preferia morrer a viver sem ela. (...) Ela acreditava na

Caderno Seminal Digital Ano 16, nº 13, V. 13 (Jan.- Jun/2010) - ISSN 1806 -9142 
justiça, acreditava que um dia se fazia justiça, que havia um povo e não um bando de gente sem alma, gente rebotalho, acreditava que o povo também deveria acreditar nisso e que eles deveriam fazer alguma coisa para que isso acontecesse. (RIBEIRO, 1984, p. 399)

Os embates entre o povo e a elite são constantes no romance. Todavia, nos discursos das personagens da camada popular, percebe-se também a crença em um tipo de unidade, ou melhor, não há um questionamento quanto à melhor forma de organização do Estado, mas ao fato de que o povo nunca é considerado em qualquer que seja tal forma de organização. Os dominadores sempre ligados aos, quando não parte dos, representantes do poder político estatal, eles, sim, é que são duramente combatidos. Assim, a resistência começa com os conspiradores da casa de Farinha, chegando ao bando de Maria da Fé. Dentre os conspiradores, destacam-se: Feliciano, escravo que, por ter presenciado a farsa de Perilo Ambrósio na batalha do Pirajá, teve a língua cortada por este; Júlio Dandão, pai de Inocêncio, escravo morto por Ambrósio, na citada batalha, (Dandão lutou e morreu na guerra dos Farrapos) e Budião, também excombatente da guerra dos Farrapos, que passa a fazer parte do bando de Maria da Fé. A primeira conspiração levada a termo pelo grupo da casa de farinha consistiu em matar por envenenamento, com infusão de ervas, - sabedoria passada por Dadinha - o Barão de Pirapuama. Após outras atuações dos conspiradores, eles também libertaram do cárcere da Bahia Bento Gonçalves, comandante da guerra dos Farrapos.

Há no romance, conforme já assinalamos, uma imbricação de eventos conhecidos da historiografia oficial com outros fictícios, o que é uma característica da metaficção historiográfica. No entanto, os primeiros são esvaziados pela força representativa dos segundos. Quer isso dizer que os eventos da historiografia oficial não teriam acontecido se não fosse a participação das figuras igualmente históricas, mas que são por aquele registro apagadas, não comparecendo nele. Não haveria vitória na guerra do Paraguai se não fossem os batalhões de negros escravos que lá foram combater pela pátria. Apesar do espírito patriótico de João Popó, e dos filhos que tivera com a sua mulher branca, quem foi para esta guerra foi Zé Popó, filho que aquele tivera com Rufina, mãe de santo de Itaparica e neta de Dadinha. Acresce-se que Zé Popó, naquele momento, já fazia parte do bando de Maria da Fé e esta apoiou a sua ida para a guerra. Sem a participação dos escravos, não haveria certamente a vitória parcial das forças de Bento Gonçalves contra o Império, e por aí vai. 
Percebe-se, então, que João Ubaldo, ao criar a linhagem de Dadinha, discute seriamente a participação dos afro-descendentes na construção do Brasil. Para tanto, compõe duas redes figurativas que às vezes se imbricam, outras não. A pátria da elite não ser a mesma pátria da esperança de Maria da Fé, cujo nome funciona como índice dos traços da personagem. A pátria dos que buscam força e inspiração na canastra de Dandão está em confronto com a pátria dos Ambrosio e Ferreira-Dutton. Como diz Magdelaine, "a construção da nação e a contradição social são, portanto, duas perspectivas que se imbricam em Viva o povo brasileiro (RIBEIRO 2003). Vejamos abaixo as falas reflexivas e divididas de Maria da Fé e de Zé Popó. A primeira foi proferida antes da guerra e a segunda compõe o discurso do ex-combatente, durante a homenagem na Câmara Municipal de Itaparica:

Teria orgulho sim (...) se a luta e o sofrimento não fossem para preservar um Brasil onde muitos trabalhavam e poucos ganhavam, onde o verdadeiro povo brasileiro, o povo que produzia (...) não tinha voz nem respeito (...) Teria orgulho se essa luta tivesse sido, como poderia ser, para defender um Brasil onde o povo governasse, um grande país, uma grande pátria em que houvesse dignidade, justiça e liberdade (...) Viva o povo brasileiro! - gritou Zé Popó da tribuna, com o punho fechado e apontado para cima. (RIBEIRO, 1984, pp 482-3)

A saudação no final do discurso de Zé Popó - "Viva o povo brasileiro!" - na voz do narrador, expressão do que vem a ser o título do livro, revela bem a contradição mencionada acima. Zé Popó não sente orgulho nenhum pela sua luta, pois o Brasil continuaria o mesmo. Sentiria orgulho se a luta tivesse proporcionado justiça; dignidade e liberdade. Por isso, tudo indica que o "viva" na fala de Popó é verbo e o que o seu desejo é que o povo brasileiro "viva" para lutar por essas bandeiras.

Vemos que o enunciador constrói uma "linhagem racial" que serve como elo de construção de uma outra face da identidade nacional. Isso não nos permite perder de vista que o que predomina na obra é a duplicidade, a ambivalência. Duas linhagens, duas raças, duas lutas, duas culturas, duas concepções de vida. Por isso, os discursos que dão forma à identidade nacional não podem ser os mesmos. Poderíamos aqui usar as palavras de Homi Bhabha, ou seja, que "estamos diante da nação dividida no interior dela própria" (BABHA, 2000), apesar de em alguns momentos, no caso de iminente invasão estrangeira, os interesses do povo serem coincidentes com os interesses da elite. 
Apesar de ser uma narrativa linear, o romance de Pepetela apresenta uma peculiaridade estrutural, que é a referencialidade temporal explicitada nos títulos dos capítulos: 1961, 1972, 1982, 1991. Tais datações somente aparentemente separam os grupos de fatos por dez anos, aproximadamente, uma vez que o leitor vai sendo informado por personagens situadas em cada uma dessas temporalidades, acerca de fatos passados. Assim, o leitor pode ir compondo o seu mosaico sobre os fatos acontecidos em tais intervalos. É claro que essa demarcação temporal proposta pelo enunciador não se faz gratuita, pois nestas datas acontecem os episódios norteadores de toda a história. Em 1961, no capítulo "A casa", a geração da utopia entra em ação e os seus militantes partem para a luta armada; em 1972, no capítulo "A chana", verifica-se a performance de Vitor Ramos em direção à fronteira da Zâmbia e, obviamente, o seu sucesso em um tempo em que se articula o fim da luta que a revolução de abril de 1974, em Portugal, consolidará e em 1982, no capítulo "O polvo", encena-se o "exílio" de Sábio na praia da Caotinha e, em 1991, cenariza-se a "abertura política" e a possibilidade de ascensão de outros valores, como a escalada para o neoliberalismo.

Pensando na figura de Sábio e tentando recortá-la, vemos, através do narrador, que, após a tomada de Benguela, a personagem resolveu morar na praia da Caotinha em uma casa abandonada, por algum português fugido com medo da guerra. Percebe-se, então, que apesar do salto narrativo, cobrem-se os dez anos transcorridos de 1972 a 1982, quando a voz narrante recupera dados necessários à ordenação da sintaxe romanesca, que também recupera a história da estruturação política da nação angolana. É também pelas lentes do Sábio que se vê a corrupção e o enriquecimento ilícito dos chefes do governo e o empobrecimento cada vez maior do povo. A improbidade administrativa e o peso da máquina estatal, como um grande cabide de emprego de funcionários incompetentes, começam a ser encenados a partir de 1982 e continuam em 1991, aumentando a pobreza e o sofrimento do povo, vítima do desgoverno reinante.

A grande verdade é que Sábio se isola ao ver naufragar as idéias da utopia. A sua discordância dos dirigentes começou na mata. Ele nos lembra uma outra personagem, também criada por Pepetela, Sem Medo, do romance Mayombe. Muitas de suas palavras, ditas durante as conversas com o Comissário, antecipam a performance de Aníbal como "herói desalentado", apesar dos vinte anos que separam a escrita dos dois romances. (Mayombe foi escrito em 1971 e A geração da utopia, em 1991/ 1992). Diz Sem Medo ao Comissário: “Os homens serão prisioneiros das estruturas que terão 
criado. Todo organismo vivo tende a cristalizar-se. (...) a fechar-se sobre si próprio" (PEPETELA, p. 22).

Sábio, como Sem medo, também desaparece da cena política. Só que a "morte" do primeiro, se é que podemos falar assim, é simbólica, em razão de seu isolamento na Caotinha. Após a independência, ele aceita receber apenas uma pequena pensão militar. Pesca para seu sustento na praia que lhe proporcionou muitas alegrias na infância, mas que também lhe rendeu um dos seus principais pesadelos: o polvo. Aníbal é a voz discordante entre os dirigentes, mesmo sem nada falar. A sua ética e autoridade falam por ele. Talvez ele exista para denunciar a incapacidade dos homens em renunciar aos valores disseminados pelo imperialismo, sobretudo o de concentração de riquezas. Como Sem Medo, fora comandante do MPLA e era respeitado, por ser justo e sábio.

Tanto o romance Viva o povo brasileiro quanto a obra A geração da utopia fazem uma espécie de recorte epistemológico na historiografia da respectiva nação a que pertence o autor, privilegiando determinados eventos e não outros. Assim, os fatos abordados pelo registro histórico - que é lacunar, segundo Paul Veyne (1987, p. 26) são ressignificados pelos autores das obras, que ora subvertem as informações das fontes, ora preenchem as lacunas nelas existentes. Quanto a esse segundo procedimento, a valorização de determinadas intrigas e de determinadas personagens, por si só, já altera aquilo que está sacramentado nas fontes históricas. Todos esses procedimentos utilizados na composição dos romances rasuram a história oficial, fazendo com que o seu sentido quase teológico seja destruído, exatamente porque personagens (heróis e heroínas) e fatos considerados verídicos são desmistificados aos olhos do leitor.

Para concluir, gostaríamos de trazer a fala da personagem Zé Popó, de Viva o povo brasileiro: "o herói pode ser qualquer um a depender de onde esteja, do que faça e de como o que faz é interpretado pelos outros", (RIBEIRO, 1984, p. 482). A importância destas palavras é que, em qualquer gesto interpretativo, nunca a interpretação se desvincula de um espaço e de um tempo histórico. Os heróis da historiografia oficial das nações, palco em que se encenam as histórias contadas, não coincidem com os perfis dos heróis desenhados dos dois romances. E assim, deste modo, os narradores propõem uma nova forma de reler a história, já que deixam claro que tanto o historiador como o romancista precisam "interpretar" o material selecionado para reescrever a história. Como salienta Hayden White (2001, p. 65): uma narrativa histórica é uma mistura de "fatos estabelecidos e inferidos, e ao mesmo tempo uma 
representação que é (...) tomada por uma explicação de todo o processo refletido na narrativa." E aí tem razão Zé popó, pois o herói também depende da interpretação para ter fixadas as bases do processo de seu reconhecimento.

\section{Referências bibliográficas:}

BHABHA, Homi. O local da cultura. Belo Horizonte: Editora da UFMG, 2003.

HUTCHEON, Linda. Poética do pós-modernismo. História, teoria, ficção. Rio de Janeiro: Imago, 1991. $\overline{1984 .}$

Linda. Narcissistic narrative: the metaficional paradox. New York: Methuen,

OLIVIERI-GODET, Rita. Memória, história e ficção em Viva o povo brasileiro de João Ubaldo Ribeiro. Université de Paris, s/d, no. 8. Disponível em $<$ http://www.geocities.com/ail.br/ail.html>. Acesso: 13/07/03.

PEPETELA. [PESTANA, Artur Carlos Maurício]. A geração da utopia. Lisboa: Dom Quixote, 1993.

PEPETELA. [PESTANA, Artur Carlos Maurício]. Yaka. São Paulo: Ática, 1985. Mayombe. São Paulo: Ática, 1984.

RIBEIRO, João Ubaldo. Viva o povo brasileiro. Rio de Janeiro: Nova Fronteira, 1984.

RIBEIRO, Magdelaine. Que bandeira é essa? Disponível em $<\mathrm{http}$ ://www.geocities.com/ail br/ail.html>. Acesso: 13/07/03.

VEYNE, Paul. Como se Escreve a História. Lisboa: Edições 70, 1987.

WHITE, Hayden. Trópicos do discurso. São Paulo: EDUSP, 2001. 